\title{
Pet food and feed applications of inulin, oligofructose and other oligosaccharides
}

\author{
E. A. Flickinger and G. C. Fahey Jr* \\ Department of Animal Sciences, University of Illinois, 132 Animal Sciences Laboratory, 1207 W. Gregory Drive, \\ Urbana, IL 61801, USA
}

\begin{abstract}
Prebiotics may be considered as functional food ingredients. They are attracting considerable interest from pet owners, pet food manufacturers, livestock producers and feed manufacturers. The most common forms of prebiotics are nondigestible oligosaccharides (NDO), including inulin, oligofructose mannanoligosaccharides, gluco-oligosaccharides, and galacto-oligosaccharides. These NDO are nondigestible by enzymes present in the mammalian small intestine, but are fermented by bacteria present in the hindgut of nonruminants. Inulin and oligofructose are present in measurable quantities in feed ingredients like wheat, wheat by-products, barley, and peanut hulls. Consumption of prebiotic oligosaccharides elicits several purported health benefits. In companion animals, prebiotics have been shown to improve gut microbial ecology and enhance stool quality. In production livestock and poultry, prebiotics are employed to control pathogenic bacteria, reduce faecal odour, and enhance growth performance. Research to date indicates positive effects of prebiotics on health status and performance of companion animals, livestock, and poultry.
\end{abstract}

Prebiotics: Fructans: Animal nutrition

\section{Introduction}

There currently exists much interest in the use of prebiotics for companion animals, livestock, and poultry as modulators of colonic bacterial populations and fermentation end-products. Prebiotics are nondigestible food ingredients that positively affect the host by selectively stimulating the activity of a limited number of beneficial colonic bacteria, resulting in improved host health (Gibson \& Roberfroid, 1995). Inulin and oligofructose are perhaps the most well studied prebiotics (for a description of these products see Roberfroid, 2002).

\section{Concentrations of inulin and oligofructose in pet food and feed ingredients}

Hussein et al. (1998) selected twenty-five common ingredients and analysed them for oligofructose concentrations (Table 1). In this study, the concentrations of three major subcomponents of oligofructose (1-kestotriose, 1,1-kestotetraose, and 1,1,1 kestopentaose) were assayed via anion exchange HPLC. No oligofructose was detected in corn, corn distiller's solubles, hominy, milo, brown rice, white rice, brewer's rice, rice hulls, seaweed, or soybean meal. On a dry matter basis, wheat co-products (bran, germ, and middlings) contained the highest concentrations of total oligofructose, followed by peanut hulls, alfalfa meal, barley, and wheat. The remaining ingredients contained very low concentrations $(<0.4 \mathrm{mg} / \mathrm{g})$ of oligofructose. While this database provides information on a number of commonly used pet food ingredients, additional analysis of components of oligofructose with longer degree of polymerization (DP) and inulin concentrations would be desirable.

Van Loo et al. (1995) reported the concentrations of inulin and oligofructose in common dietary ingredients (Table 1). Their analyses quantified glucose and fructose released by enzymatic hydrolysis of the food or plant material and assayed oligofructose (DP up to ten) and inulin contents with a DP of two to sixty (Quemener et al. 1994). Values are reported on an 'as-is' basis and indicate the range of concentrations determined due to variation in sources of each food or plant material. Garlic contained the highest concentration of oligofructose. Wheat and dried onion contained similar amounts of oligofructose, while rye flour and barley contained the lowest concentrations. The authors concluded that inulin and oligofructose are present in significant amounts in a wide variety of common foods and food ingredients. 
Table 1. Inulin/oligofructose content of selected feeds, pet foods and food ingredients

\begin{tabular}{lcc}
\hline Item & $\begin{array}{c}\text { Oligofructose content* } \mathrm{mg} / \mathrm{g} \\
\text { (dry matter basis) }\end{array}$ & $\begin{array}{c}\text { Inulin and oligofructose content } \\
\mathrm{mg} / \mathrm{g} \text { (as-is basis) }\end{array}$ \\
\hline Alfalfa meal & 2.24 & $0.05-0.10$ \\
Barley & 1.92 & \\
Beet pulp & 0.05 & \\
Canola meal & 0.04 & $0.98-1.60$ \\
Corn gluten feed & 0.09 & \\
Corn gluten meal & 0.34 & $0.11-0.75$ \\
Garlic & 0.36 & \\
Oats & 0.12 & $0.05-0.10$ \\
Oat groats & 2.40 & $0.10-0.40$ \\
Onion, dried & 0.14 & \\
Peanut hulls & & \\
Rice bran & 0.12 & \\
Rye flour & 1.36 & \\
Soybean hulls & 4.00 & \\
Wheat & 4.68 & \\
Wheat bran & 5.07 & \\
Wheat germ & & \\
Wheat middlings & & \\
\hline
\end{tabular}

* Determined by Hussein et al. (1998) as sum of 1-kestotriose +1,1-kestotetraose + 1,1,1-kestopentaose.

†Determined by Van Loo et al. (1995) as sum of inulin and oligofructose with DP of 2 to 60

\section{Applications of inulin and oligofructose in animal nutrition}

Perhaps the best-known nutritional effect of inulin and oligofructose is their ability to modify the composition of the intestinal microflora (e.g. increased numbers of bifidobacteria) and their metabolic activity in the large intestine (Roberfroid et al. 1998; Van Loo et al. 1999). In general, most gut bacteria can be divided into groups that exert detrimental effects (staphylococci, clostridia, and veillonella) or those that benefit the host (bifidobacteria, lactobacilli, and eubacteria). Detrimental influences include diarrhoea, infection, and digesta putrefaction, as well as the absorption and metabolism of mutagenic and carcinogenic chemicals (Rowland et al. 1985). Conversely, beneficial bacteria bestow positive effects on the host and may inhibit the growth of harmful bacteria, including E. coli, C. perfringens, salmonellae, listeria, campylobacter, and shigellas (Gibson \& Wang, 1994; Araya-Kojima et al. 1995). Homma (1988) described bifidobacteria as a resistance factor in humans based on defence against pathogens, infections and reduction of serum cholesterol. Other beneficial effects attributed to bacteria include stimulation of immune function, increased mineral absorption, and synthesis of vitamins (Gibson \& Roberfroid, 1995). In addition to their effects on gastrointestinal characteristics and systemic metabolism, inulin and oligofructose have been postulated to enhance performance responses of poultry and rabbits (Ammerman et al. 1988, 1989; Morisse et al. 1993). Finally, there are some microbial species that exert both negative and positive effects (e.g. streptococci, E. coli, and bacteroides) and, therefore, are considered neutral (Gibson \& Roberfroid, 1995).

\section{Companion animal studies}

Flickinger et al. (unpublished data) supplemented adult female hounds with $0,1,2$, or $3 \mathrm{~g}$ oligofructose (from sucrose)/d in gelatin capsules. The basal diet consisted of $372 \mathrm{~g} / \mathrm{kg}$ chicken protein, $196 \mathrm{~g} / \mathrm{kg}$ corn, $195 \mathrm{~g} / \mathrm{kg}$ brewer's rice, $130 \mathrm{~g} / \mathrm{kg}$ oil, $40 \mathrm{~g} / \mathrm{kg}$ beet pulp, $30 \mathrm{~g} / \mathrm{kg}$ liquid digest, $10 \mathrm{~g} / \mathrm{kg}$ dried brewer's yeast, and $27 \mathrm{~g} / \mathrm{kg}$ vitamin-mineral premix. Compared to the control, supplemental oligofructose (from sucrose) $(3 \mathrm{~g} / \mathrm{d})$ tended $(P<0 \cdot 10)$ to decrease faecal concentrations of Clostridium perfringens (10.04 v. $\left.9.67 \log _{10} \mathrm{CFU} / \mathrm{g}\right)$ and increased $(P<0.05)$ total aerobes ( 8.52 v. $\left.9.32 \log _{10} \mathrm{CFU} / \mathrm{g}\right)$. There were no differences among treatments in total anaerobes, bifidobacteria or lactobacilli. However, results from a second study by the same group differed. Sixteen adult male beagles were fed a corn-based diet with or without 3,6 or $9 \mathrm{~g} / \mathrm{kg}$ supplemental oligofructose (from sucrose) for 18 days. Dogs fed the highest level of oligofructose tended $(P<0 \cdot 10)$ to have higher concentrations of bifidobacteria $\left(9.80\right.$ v. $9.40 \log _{10}$ $\mathrm{CFU} / \mathrm{g}$ ) in their faeces when compared with the control group. Differences in the results of these two studies may be due to variability in basal diet formulations (meat- $v$. corn- based diets) and in methods of administering oligofructose (capsule $v$. incorporation into an extruded diet). Also, the diet used in the second study contained some wheat grain that contained fructans.

In a recent study from our laboratory, Swanson et al. (unpublished data) fed ileally cannulated dogs a meatbased premium diet supplemented either with $1 \mathrm{~g} / \mathrm{d}$ oligofructose (from sucrose), $1 \mathrm{~g} / \mathrm{d}$ mannanoligosaccharides (MOS), $1 \mathrm{~g} / \mathrm{d}$ oligofructose (from sucrose) $+1 \mathrm{~g} \mathrm{MOS}$, or $1 \mathrm{~g} / \mathrm{d}$ sucrose (control) administered via gelatin capsules. Dogs were adapted to their respective diets for 10 days, followed by a 4-day collection of ileal effluent and faeces in a $4 \times 4$ Latin square design. Although neither oligofructose nor MOS altered faecal output, moisture content, or score, MOS decreased $(P<0.05)$ faecal total aerobes and tended $(P=0.13)$ to increase faecal concentrations of lactobacilli. Supplemental MOS also increased $(P<0.05)$ serum lymphocyte concentrations and tended $(P=0.14)$ to increase serum IgA concentrations. 
Supplemental oligofructose tended to decrease concentrations of three chemical indicators of faecal odour, tryptamine $(P=0 \cdot 11)$, tyramine $(P=0 \cdot 15)$, and indole $(P<0 \cdot 10)$. From these data, it appears that MOS may favourably alter the composition of the colonic bacteria and elicit a systemic immune response, while oligofructose may reduce faecal odour. However, when combined, oligofructose and MOS did not act synergistically.

\section{Poultry, swine, and rabbit studies}

Feeding fructans may be a practical strategy for controlling pathogenic bacteria in chickens. Fukata et al. (1999) fed 1day-old chicks an antibiotic-free diet supplemented either with probiotic bacteria (competitive exclusion; CE), $1 \mathrm{~g} /$ $\mathrm{kg}$ dietary oligofructose (from sucrose), or probiotics + $1 \mathrm{~g} / \mathrm{kg}$ oligofructose for 7 days. At 1 day after oral inoculation with $10^{8} \mathrm{CFU}$ of Salmonella enteritidis, only chicks fed $\mathrm{CE}$ had fewer $(P<0.05) S$. enteritidis $\left(\log _{10}\right.$ $\mathrm{CFU} / \mathrm{g})$ organisms recovered in caecal digesta $(2.35 \mathrm{v}$. $4.57,4.05$, and 2.76 for CE $v$. control, oligofructose, and $\mathrm{CE}+$ oligofructose, respectively). In a second experiment, 1-day-old chicks were administered the same treatments, but were adapted to diets for 21 days prior to inoculation with $S$. enteritidis. Chicks receiving oligofructose or CE + oligofructose exhibited lower $(P<0.05)$ caecal concentrations of $S$. enteritidis at 1 day after inoculation $(2.45$ and $1.76 v .4 .31$ and 4.04 for oligofructose, CE + oligofructose, control, and $\mathrm{CE}$, respectively), suggesting that addition of low levels of oligofructose to the diet of chicks receiving a probiotic may reduce Salmonella colonisation.

Two sources of dietary fructan were evaluated in a study by Chambers et al. (1997). Chicks were fed diets supplemented with either no carbohydrates (control), $80 \mathrm{~g} / \mathrm{kg}$ Jerusalem artichoke flour providing $50 \mathrm{~g} / \mathrm{kg}$ inulin (JAF), or $50 \mathrm{~g} / \mathrm{kg}$ refined chicory inulin. Chicks were exposed to Salmonella by being reared with seeder chicks gavaged with $10^{7}$ CFU of naladixic acid-resistant S. typhimurium. At 6 weeks of age, the average Salmonella score of JAFfed chicks was higher $(P<0.05)$ than that of control-fed chicks, while the score of chicory inulin-fed chicks was lower $(P<0.05)$ than for other groups. Further research needs to be done to elucidate the effects of different sources of inulin and/or oligofructose on Salmonella colonisation of broiler caeca.

In addition to their effects on gastrointestinal characteristics, inulin and oligofructose have been postulated to enhance performance responses of livestock. Houdijk et al. (1998) investigated the effects of oligofructose and transgalacto-oligosaccharides (TOS) in growing pigs. Nine-week-old pigs were fed diets supplemented with either 7.5 or $15 \mathrm{~g} / \mathrm{kg}$ oligofructose or 10 or $20 \mathrm{~g} / \mathrm{kg}$ TOS for 6 weeks. The basal diet contained no additional copper, antibiotics, or probiotics. In the first week, supplemental oligosaccharides resulted in decreased $(P<0.05)$ daily weight gain (control, $953 \mathrm{~g} ; 7.5 \mathrm{~g} / \mathrm{kg}$ oligofructose, $860 \mathrm{~g} ; 15 \mathrm{~g} / \mathrm{kg}$ oligofructose, $750 \mathrm{~g} ; 10 \mathrm{~g} / \mathrm{kg}$ TOS, $765 \mathrm{~g}$; and $20 \mathrm{~g} / \mathrm{kg}$ TOS, $770 \mathrm{~g}$ ) and feed conversion efficiency (feed/gain; control, $1.16 ; 7.5 \mathrm{~g} / \mathrm{kg}$ oligofructose, $1.23 ; 15 \mathrm{~g} / \mathrm{kg}$ oligofructose, $1.35 ; 10 \mathrm{~g} / \mathrm{kg}$ TOS, 1.40 ; and
$20 \mathrm{~g} / \mathrm{kg}$ TOS, 1.24). Dry matter intake was numerically $(P=0 \cdot 10)$ reduced in oligofructose and TOS treatment groups (control, $1104 \mathrm{~g} ; 7.5 \mathrm{~g} / \mathrm{kg}$ oligofructose, $1061 \mathrm{~g}$; $15 \mathrm{~g} / \mathrm{kg}$ oligofructose, $982 \mathrm{~g} ; 10 \mathrm{~g} / \mathrm{kg}$ TOS, $1036 \mathrm{~g}$; and $20 \mathrm{~g} / \mathrm{kg}$ TOS, $957 \mathrm{~g}$ ). During weeks 2 and 3, a similar negative trend occurred, but the differences were not significant. In contrast, during weeks 4-6, oligofructose and TOS supplementation resulted in numerically $(P=0.08)$ increased daily weight gains (control, $861 \mathrm{~g} ; 7.5 \mathrm{~g} / \mathrm{kg}$ oligofructose, $1056 \mathrm{~g} ; 15 \mathrm{~g} / \mathrm{kg}$ oligofructose, $981 \mathrm{~g} ; 10 \mathrm{~g} / \mathrm{kg}$ TOS, $964 \mathrm{~g}$; and $20 \mathrm{~g} / \mathrm{kg}$ TOS, $1032 \mathrm{~g})$, numerically $(P>0.05)$ greater feed consumption (control, $1655 \mathrm{~g} ; 7.5 \mathrm{~g} / \mathrm{kg}$ oligofructose, $1852 \mathrm{~g} ; 15 \mathrm{~g} / \mathrm{kg}$ oligofructose, $1756 \mathrm{~g} ; 10 \mathrm{~g} / \mathrm{kg}$ TOS, $1850 \mathrm{~g}$; and $20 \mathrm{~g} / \mathrm{kg}$ TOS, $1830 \mathrm{~g}$ ) and numerically $(P=0.08)$ enhanced feed conversion efficiency (feed/gain; control, $1.91 ; 7.5 \mathrm{~g} / \mathrm{kg}$ oligofructose, $1.73 ; 15 \mathrm{~g} / \mathrm{kg}$ oligofructose, $1.83 ; 10 \mathrm{~g} / \mathrm{kg}$ TOS, $1.93 ;$ and $20 \mathrm{~g} / \mathrm{kg}$ TOS, 1.78). Differences between the first and last 3-week periods of this study may indicate that young pigs require an adaptation period to dietary oligosaccharides; initially, lower performance can be offset with compensatory growth. The initial depression in feed intake may coincide with fluctuations in colonic microflora ecology, suggesting the role of a non-specific immune response in the observed anorexia.

Other investigators have not found similar effects in swine. Farnworth et al. (1992) reported that $15 \mathrm{~g} / \mathrm{kg}$ oligofructose (from sucrose) or JAF in weanling pig diets did not significantly affect daily feed intake, weight gain, or feed efficiency. However, the authors speculated that the lack of an effect was due to too low a concentration of dietary oligofructose. Similarly, Olsen \& Maribo (1999) reported that $16.5 \mathrm{~g} / \mathrm{kg}$ dietary inulin fed to weanling piglets did not result in a significant difference in average daily weight gain or feed efficiency. The lack of response to supplemental inulin may have been caused by a high fructan content of the basal diet due to wheat and barley inclusion.

In rabbits experimentally infected with E. coli $\mathrm{O} 103$ and fed either 0 or $2.5 \mathrm{~g} / \mathrm{kg}$ dietary oligofructose, fewer $(P<0.05)$ rabbits exhibited clinical signs of enteritis (diarrhoea) in the oligofructose group $(14.8 \%)$ as compared to the control group (46.4\%) (Morisse et al. 1993). However, mortality rate was not significantly different amongst the treatments (17.9 and $22.2 \%$ for control and oligofructose treatments, respectively). Among surviving animals, oligofructose-fed rabbits tended $(P>0.05)$ to have heavier body weights (2454 v. $2359 \mathrm{~g})$ and had numerically $(P>0.05)$ higher average daily weight gains $(33.5 v .32 .6 \mathrm{~g} / \mathrm{d})$ as compared to the control. While oligofructose supplementation reduced morbidity, it did not significantly improve mortality or growth performance of rabbits.

\section{Future research directions}

Many issues remain unresolved concerning prebiotic oligosaccharides, including the establishment of accurate relationships among the composition of the colonic microflora, gastrointestinal tract health and clinical or performance outcomes observed in the animal. Essential to the determination of these relationships is an in-depth 
understanding of the mechanisms that provide the basis for any observed effect. Another unknown is whether fructans can be used interchangeably. Optimal inulin and/or oligofructose inclusion levels in diets have yet to be established for most animal species. It is unknown whether combinations of different oligosaccharides can elicit diverse beneficial effects, exert a synergistic effect, or perhaps a negative effect. Besides blending prebiotics, synbiotic therapy (coupling probiotic bacteria with prebiotic substrates) perhaps could have a greater impact on the intestinal microflora by nourishing indigenous beneficial bacteria and directly increasing numbers of favourable microbes.

\section{Summary}

A relatively small amount of research exists concerning supplementation of fructans and other oligosaccharides in the diets of companion animals, livestock, and poultry. Studies to date indicate a generally positive effect of fructans on colonic microbial ecology, host health, and growth performance. However, more research remains to be done to determine the appropriate role of these oligosaccharides in animal nutrition.

\section{References}

Ammerman E, Quarles C \& Twining PV (1988) Broiler response to the addition of dietary fructooligosaccharides. Poultry Science 67, (Suppl), 1, (Abstr.).

Ammerman E, Quarles C \& Twining PV (1989) Evaluation of fructooligosaccharides on performance and carcass yield of male broilers. Poultry Science 68, (Suppl), 167, (Abstr.).

Araya-Kojima T, Yaeshima T, Ishibashi N, Shimamura S \& Hayasawa H (1995) Inhibitory effects of Bifidobacterium longum BB536 on harmful intestinal bacteria. Bifidobacteria Microflora 14, 59-66.

Chambers JR, Spencer JL \& Modler HW (1997) The influence of complex carbohydrates on Salmonella typhimurium colonization, $\mathrm{pH}$, and density of broiler ceca. Poultry Science 76, 445-451.

Farnworth ER, Modler HW, Jones JD, Cave N, Yamazaki H \& Rao AV (1992) Feeding Jerusalem artichoke flour rich in fructooligosaccharides to weanling pigs. Canadian Journal of Animal Science 72, 977-980.

Fukata T, Sasai K, Miyamoto T \& Baba E (1999) Inhibitory effects of competitive exclusion and fructooligosaccharide, singly and in combination, on Salmonella colonization of chicks. Journal of Food Protection 62, 229-233.

Gibson GR \& Roberfroid MB (1995) Dietary modulation of the human colonic microbiota: introducing the concept of prebiotics. Journal of Nutrition 125, 1401-1412.

Gibson GR \& Wang X (1994) Regulatory effects of bifidobacteria on the growth of other colonic bacteria. Journal of Applied Bacteriology 77, 412-420.

Homma N (1988) Bifidobacteria as a resistance factor in human beings. Bifidobacteria Microflora 7, 35-43.

Houdijk JGM, Bosch MW, Verstegen MWA \& Berenpas HJ (1998) Effects of dietary oliogsaccharides on the growth performance and faecal characteristics of young growing pigs. Animal Feed Science and Technology 71, 35-48.

Hussein HS, Campbell JM, Bauer LL, Fahey GC Jr, Hogarth AJCL, Wolf BW \& Hunter DE (1998) Selected fructooligosaccharide composition of pet food ingredients. Journal of Nutrition 128, 2803S-2805S.

Morisse JP, Maurice R, Boilletot E \& Cotte JP (1993) Assessment of the activity of fructooligosaccharide on different caecal parameters in rabbits experimentally infected with E. coli $\mathrm{O} 103$. Annales de Zootechnie 42, 81-87.

Olsen LE \& Maribo H (1999) Company products and feed for piglets. In Danish Slaughterhouse Report \#443, [FUT Igalac and F Bokashi, editors]. Denmark: National Committee for Pig Breeding, Health and Production.

Quemener B, Thibault J-F \& Coussement P (1994) Determination of inulin and $\mathrm{OF}$ in food products, and integration in the AOAC method for measurement of total dietary fiber. LebensmittelWissenschaft und-Technologie 27, 125-132.

Roberfroid MB, Van Loo JA \& Gibson ER (1998) The bifidogenic nature of chicory inulin and its hydrolysis products. Journal of Nutrition 128, 11-19.

Roberfroid M (2002) Functional Foods: concepts and application to inulin and oligofructose. British Journal of Nutrition 87, S139-S143, this issue.

Rowland IR, Mallett AK \& Wise A (1985) The effect of diet on the mammalian gut flora and its metabolic activities. CRC Critical Reviews in Toxicology 16, 31-103.

Van Loo J, Coussement P, Leenheer LD, Hoebregs H \& Smits G (1995) On the presence of inulin and OF as natural ingredients in the western diet. Critical Reviews in Food Science and Nutrition 35, 525-552.

Van Loo J, Cummings JH, Delzenne N, Englyst HN, Franck A, Hopkins MJ, Kok N, Macfarlane GT, Newton DF, Quigley ME, Roberfroid MR, Van Vliet T \& Van den Heuvel EGH (1999) Functional food properties of nondigestible oligosaccharides: a consensus report from the ENDO project (DGXII AIRII-CT94-1095). British Journal of Nutrition 81, 121-132. 